\title{
A comparative study on diabetes self-management in pregnant women with gestational diabetes and pre-existing diabetes.
}

\author{
Radiana Staynova $^{1}$, Stanislav Gueorguiev ${ }^{1}$, Elina Petkova-Gueorguieva1 ${ }^{1}$, Penka Petleshkova ${ }^{2,3}{ }^{*}$ \\ ${ }^{1}$ Department of Pharmaceutical Sciences, Faculty of Pharmacy, Medical University-Plovdiv, Bulgaria \\ ${ }^{2}$ Department of Obstetrics and Gynecology, Faculty of Medicine, Medical University-Plovdiv, Bulgaria \\ ${ }^{3}$ St George University Hospital, Plovdiv, Bulgaria
}

\begin{abstract}
Pre-existing diabetes mellitus (Types 1 and 2) and gestational diabetes mellitus (GDM) are the most common medical complications in pregnancy. The aim of this study was to evaluate and compare the lifestyle habits of pregnant women with pre-existing diabetes mellitus (PDM) and GDM. A comparativedescriptive study on diabetes self-management during pregnancy was carried out using pre-validated self-administrated questionnaire. A total of 99 women with PDM and GDM participated in the study. The questionnaire provided information about patient demographics, obstetric history, diabetes history, self-monitoring of blood glucose (SMBG), dietary habits and physical activity. The two groups of pregnant women did not differ significantly with regard to demographic and obstetric characteristics. Only 26.8\% of the women in GDM group adhered to strict SMBG and were tested daily (compared with $\mathbf{8 3 . 7 \%}$ in PDM group, $\mathbf{p}<0.001$ ). There were significant differences regarding dietary habits-91.1\% of the women in GDM group reported eating healthy balanced meals compared with 62.2\% in PDM group, $\mathrm{p}=0.001$. Physical activity habits were similar between both groups. This study confirms the importance of self-care and healthy lifestyle habits during pregnancy. Every pregnant woman with PDM or GDM should obtain appropriate diabetes self-management education and support.
\end{abstract}

Keywords: Pre-existing diabetes mellitus, Gestational diabetes mellitus, Self-management, Healthy lifestyle. Accepted on October 11, 2018

\section{Introduction}

Pre-existing diabetes mellitus (Types 1 and 2) and gestational diabetes mellitus (GDM) are the most common medical complications in pregnancy. According to the latest edition of IDF Diabetes Atlas, 16.2\% of live births in 2017 were affected by some form of hyperglycemia in pregnancy. It is estimated that the vast majority of cases were due to GDM (86.4\%), while the remaining $13.6 \%$ were due to type 1 and type 2 diabetes, existing before or detected for the first time during pregnancy [1].

Numerous studies involving women with pre-existing diabetes mellitus (PDM) have shown the greater risk of adverse pregnancy outcomes including preterm delivery, stillbirth, preeclampsia, perinatal mortality, neonatal morbidity, caesarean delivery, macrosomia and congenital malformation compared to the non-diabetic population [2-7]. In order to achieve a normal pregnancy outcome and to reduce the risk of maternal and neonatal complications, the worldwide diabetes guidelines recommend all women with PDM to be referred to pre-conception counselling [8-10].
Unlike PDM, GDM is a temporary condition that usually disappears after delivery [1]. Unmanaged GDM is associated with short- and long-term complications for both mother and child [1,8-10]. Hyperglycaemia in GDM affects the development of the fetus and increases the risk of macrosomia and birth complications as well as type 2 diabetes and metabolic syndrome later in life [9].

Care for pregnant women with diabetes requires a multidisciplinary approach with close collaboration in a health team including an endocrinologist experienced in the treatment of pregnant women with diabetes, obstetricians, a registered dietitian, a diabetes nurse specialist, neonatologist, pharmacist and other professionals such as ophthalmologist and nephrologist [8,11]. One of the main components for successful diabetes management during pregnancy is patient education. Clement defines diabetes self-management education as 'a process of providing the person with diabetes the knowledge and skills needed to perform self-care, manage crises, and make lifestyle changes required to successfully manage this disease' [12]. The main goal of diabetes selfmanagement education during pregnancy is to acquire the necessary knowledge and skills for adaptation and self-care. Effective diabetes management before, during and after 
pregnancy is very important in reducing the risk of adverse pregnancy outcomes [13].

For successful management of diabetes in pregnancy, women should be educated about the following components: selfmonitoring of blood glucose (SMBG); nutritional management; physical activity; pharmacological treatment and weight management. SMBG is a key element of diabetes management during pregnancy and allows healthcare providers to choose the most effective therapeutic option (diet combined with physical activity, insulin therapy, etc.) [14]. Numerous studies have shown that regular SMBG leads to reduction in maternal and neonatal complications $[15,16]$.

Another important component of diabetes management during pregnancy is lifestyle modification [9]. Regardless of the type of diabetes, pregnant women should be advised on appropriate meal plan, optimal weight gain and moderate physical activity [17]. Excessive weight gain during pregnancy is associated with a higher frequency of maternal complications and longterm consequences for the women and their children $[18,19]$. It is recommended that pregnant women with diabetes follow an individualized medical nutrition plan developed by a registered dietitian [9]. All pregnant women should be encouraged to perform moderate physical activity for at least $30 \mathrm{~min}$ a day unless there are explicit medical contraindications to this effect [17]. In pregnant women with diabetes, light cardio exercises such as walking are recommended, especially after meals [20].

The aim of the present study was to evaluate and compare lifestyle habits, including SMBG, eating habits and physical activity in women with PDM and GDM.

\section{Material and Methods}

\section{Study design}

This was a comparative-descriptive study on diabetes selfmanagement during pregnancy. An informed consent was obtained by every pregnant woman who decided to participate in the study. The survey was conducted between January 2017 and August 2017 in the city of Plovdiv and Sofia and covered two medical establishments: Clinic of Obstetrics and Gynecology at St. George University Hospital, Plovdiv and University Obstetrics and Gynecology Hospital "Maichin Dom", Sofia. The study was approved by the Scientific Ethics Committee of the Medical University-Plovdiv.

\section{Study participants}

The study population included pregnant women with GDM and PDM (Types 1 and 2), with a singleton pregnancy and aged 18-45 y. Exclusion criteria from the study were pregnant women under the age of 18, unable to write, read and understand the Bulgarian language. All women meeting the inclusion criteria were invited to participate in the study. A total of 99 women with PDM and GDM accepted to participate. The respondents were divided into two groupswomen with GDM and PDM.

\section{Data collection}

A self-administrated questionnaire was developed for the purpose of the study. A pilot testing among small sample of pregnant women was performed for initial validation. The questionnaire was design in a language familiar to the target audience and included short and simple questions. Each question was given instructions to help respondents to easily fill out the answers. Items related to the socio-demographic characteristics and obstetric details of the respondents (age, education, occupation, marital status, number of pregnancies, type of diabetes, treatment), information on SMBG, eating habits and physical activity were included.

\section{Statistical analysis}

The Statistical Package for the Social Sciences (SPSS) v.17 was used to process the data. Descriptive statistics were applied to summarize the socio-demographic characteristics of the respondents. The continuous variables are represented as mean and standard deviation, and the categorical-as frequencies and percentages. The Chi-square test was applied to search for a relationship between two categorical variables. Man-Whitney's nonparametric test was used to compare continuous variables in independent samples. P-value $\leq 0.05$ was considered significant.

\section{Results}

\section{Socio-demographic and obstetric characteristics}

The socio-demographic and obstetric characteristics of participants are presented in Table 1. A total of 99 women who met the inclusion criteria accepted to participate in the study. Fifty-six of women (56.6\%) were with GDM and 43 (43.4\%) reported for PDM (Types 1 and 2). The mean age of women was $31.38(4.68 \mathrm{y})$. Most of the women who took part in the study (39.4\%) were aged between 26-30 y. Among all respondents, $75.8 \%$ reported university degree, $22.2 \%$ of women had secondary school grade and only $2.0 \%$ reported primary school education. As regards marital status, the majority of women from both groups $(65.7 \%)$ were married or reported cohabitating (30.3\%). Only $3.0 \%$ of the respondents were single and $1.0 \%$ were divorced. There were no significant differences between the two groups in regard to demographic characteristics, with the exception of employment status-32.6\% of women in the PDM group reported as unemployed, compared with 5.4\% for women with GDM ( $p=0.001)$.

Approximately half of the women who took part in the study $(56.6 \%)$ were in the third trimester of pregnancy during the survey. There was a statistically significant difference in gestational age between the two groups-only $7.1 \%$ of women in GDM group were in the first trimester during the study compared with $23.3 \%$ in PDM group $(\mathrm{p}=0.032)$. In the GDM group $66.1 \%$ of women were in the third trimester, followed by those in the second trimester- $26.8 \%$. The reason for this is that the screening for GDM is done between 24 and 28 gestational weeks. In regard to diabetes treatment, the majority of women 
A comparative study on diabetes self-management in pregnant women with gestational diabetes and pre-existing diabetes

with GDM (85.7\%) achieved successful control only through healthy diet and exercise.

Table 1. Socio-demographic and obstetric characteristics of the survey respondents.

\begin{tabular}{|c|c|c|c|c|}
\hline \multirow[t]{2}{*}{ Characteristics } & $\begin{array}{l}\text { PDM } \\
\text { group } \\
(n=43)\end{array}$ & $\begin{array}{l}\text { GDM } \\
\text { group } \\
(n=56)\end{array}$ & $\begin{array}{l}\text { Total } \\
(n=99)\end{array}$ & \multirow[t]{2}{*}{ p-value } \\
\hline & $\mathbf{N}(\%)^{*}$ & $\mathbf{N}(\%)^{*}$ & $\mathbf{N}(\%)^{*}$ & \\
\hline Age in years, mean (SD) & $\begin{array}{l}30.98 \\
(4.85)\end{array}$ & $\begin{array}{l}31.70 \\
(4.56)\end{array}$ & $\begin{array}{l}31.38 \\
(4.68)\end{array}$ & $p=0.552^{a}$ \\
\hline \multicolumn{4}{|l|}{ Education } & \multirow{4}{*}{$p=0.094^{b}$} \\
\hline Primary & $2(4.7)$ & $0(0.0)$ & $2(2.0)$ & \\
\hline Secondary & $12(27.9)$ & $10(17.9)$ & $22(22.2)$ & \\
\hline University & $29(67.4)$ & $46(82.1)$ & $75(75.8)$ & \\
\hline
\end{tabular}

\begin{tabular}{llll}
\hline Marital status & & \\
\cline { 1 - 3 } Single & $2(4.7)$ & $1(1.8)$ & $3(3.0)$ \\
\cline { 1 - 3 } Cohabitation & $11(25.6)$ & $19(33.9)$ & $30(30.3)$ \\
\cline { 1 - 3 } Married & $30(69.8)$ & $35(62.5)$ & $65(65.7)$ \\
\hline Divorced & $0(0.0)$ & $1(1.8)$ & $1(1.0)$
\end{tabular}

\begin{tabular}{llll}
\hline Occupation & & \\
\cline { 1 - 3 } Employed & $28(65.1)$ & $49(87.5)$ & $77(77.8)$ \\
\cline { 1 - 3 } Home-working & $1(2.3)$ & $2(3.6)$ & $3(3.0)$ \\
\cline { 1 - 3 } Student & $0(0.0)$ & $2(3.6)$ & $2(2.0)$ \\
\hline Unemployed & $14(32.6)$ & $3(5.4)$ & $17(17.2)$
\end{tabular}

\section{Gestational age}

\begin{tabular}{llll}
\hline $1^{\text {st }}$ trimester & $10(23.3)$ & $4(7.1)$ & $14(14.1)$ \\
\hline $2^{\text {nd }}$ trimester & $14(32.6)$ & $15(26.8)$ & $29(29.3)$ \\
\hline $3^{\text {rd }}$ trimester & $19(44.2)$ & $37(66.1)$ & $56(56.6)$ \\
\hline
\end{tabular}

\begin{tabular}{llll}
\hline \multicolumn{2}{l}{ Number of pregnancies } & & \\
\cline { 1 - 3 } Primigravida & $21(48.8)$ & $29(51.8)$ & $50(50.5)$ \\
\cline { 1 - 2 }$\geq 2$ & $22(51.2)$ & $27(48.2)$ & $49(49.5)$
\end{tabular}

\begin{tabular}{llll}
\hline $\begin{array}{l}\text { Family history } \\
\text { diabetes }\end{array}$ & of & \\
\cline { 1 - 3 } Yes & $19(44.2)$ & $29(51.8)$ & $48(48.5)$ \\
\cline { 1 - 3 } No & $24(55.8)$ & $27(48.2)$ & $51(51.5)$ \\
\hline Diabetes treatment & & & \\
\hline Diet+exercise & $2(4.7)$ & $48(85.7)$ & $50(50.5)$ \\
\hline Insulin (MDI) & $39(90.7)$ & $8(14.3)$ & $47(47.5)$ \\
\hline Insulin (CSII) & $2(4.7)$ & $0(0.0)$ & $2(2.0)$ \\
\hline
\end{tabular}

Abbreviations: CSII: Continuous Subcutaneous Insulin Infusion; GDM Gestational Diabetes Mellitus; MDI: Multiple Daily Injections; PDM: Pre-Existing
Diabetes Mellitus; ${ }^{a} p$-value was calculated by Mann-Whitney $U$ test. ${ }^{b} p$-value was calculated by Chi-square test. "The sum of the percentages for some of the items may exceed 100 due to rounding.

In the PDM group, $95.4 \%$ of women are on insulin therapy, with $90.7 \%$ receiving multiple daily injections and $4.7 \%$ continuous subcutaneous insulin infusion (Table 1).

\section{Self-monitoring of blood glucose during pregnancy}

Statistically significant differences were found in regard to the frequency of blood glucose measurement between the two groups (Table 2). Significantly lower was the frequency of daily SMBG in women with GDM compared to those with PDM. Only 15 (26.8\%) respondents with GDM adhere to strict SMBG and measure their levels every day, compared to $83.7 \%$ for women with PDM $(\mathrm{p}<0.001)$.

Table 2. Frequency of SMBG among pregnant women enrolled in the survey.

\begin{tabular}{|c|c|c|c|c|}
\hline \multirow{2}{*}{$\begin{array}{l}\text { Frequency of } \\
\text { blood glucose } \\
\text { measurement }\end{array}$} & $\begin{array}{l}\text { PDM group } \\
(n=43)\end{array}$ & $\begin{array}{l}\text { GDM } \\
(n=56)\end{array}$ & Total $(n=99)$ & \multirow[t]{2}{*}{ p-value } \\
\hline & N (\%) & N (\%) & $\mathbf{N}(\%)$ & \\
\hline Every day & $36(83.7)$ & $15(26.8)$ & $51(51.5)$ & $P<0.001^{a}$ \\
\hline 2-4 times a week & $6(14.0)$ & $8(14.3)$ & $14(14.1)$ & \\
\hline Once weekly & $1(2.3)$ & $4(7.1)$ & $5(5.1)$ & \\
\hline $\begin{array}{l}\text { Several times in } \\
\text { month }\end{array}$ & $0(0.0)$ & $29(51.8)$ & $29(29.3)$ & \\
\hline${ }^{a} p$-value was calc & d by Chi-ss & are test & & \\
\hline
\end{tabular}

\section{Nutritional habits and physical activity during pregnancy}

Tables 3 and 4 present the results from the survey related to dietary habits and physical activity of the respondents. Pregnant women were asked to answer whether they had gone to a registered dietitian to develop an individualized meal plan that complied with the requirements of diabetes and pregnancy. It was found that only $20.2 \%$ of the respondents consulted a registered dietitian. There were no statistically significant differences between the groups. Of all the women who participated in the study, $78(78.8 \%)$ responded that they were eating healthy and balanced meals during pregnancy. Twentyone women $(21.2 \%)$ had not changed their eating habits. There was a statistically significant difference in the intake of healthy balanced meals $(91.1 \%$ in GDM group compared to $62.8 \%$ in PDM group, $\mathrm{p}=0.001)$. The survey also included questions about harmful habits such as smoking (Table 3).

Pregnant women taking part in the present study found it difficult to carry out daily physical activity (Table 4). There were no statistically significant differences in the frequency and duration of performed physical activity between the two groups. 
Table 3. Eating and lifestyle habits of the survey respondents.

\begin{tabular}{|c|c|c|c|c|}
\hline \multirow{2}{*}{ Characteristics } & PDM group ( $n=43)$ & GDM group $(n=56)$ & Total $(n=99)$ & \multirow{2}{*}{ p-value ${ }^{a}$} \\
\hline & $N(\%)^{*}$ & $N(\%)^{*}$ & $\mathrm{~N}(\%)^{*}$ & \\
\hline \multicolumn{5}{|c|}{ Eating healthy balanced meals } \\
\hline Yes & $27(62.8)$ & $51(91.1)$ & 78 (78.8) & \multirow{2}{*}{$p=0.001$} \\
\hline No & $16(37.2)$ & $5(8.9)$ & $21(21.2)$ & \\
\hline \multicolumn{5}{|c|}{ Individualized medical nutrition plan } \\
\hline Yes & $8(18.6)$ & $12(21.4)$ & $20(20.2)$ & \multirow{2}{*}{$p=0.804$} \\
\hline No & 35 (81.4) & $44(78.6)$ & $79(79.8)$ & \\
\hline \multicolumn{5}{|l|}{ Prenatal vitamins use } \\
\hline Yes & $29(67.4)$ & $43(76.8)$ & $72(72.7)$ & \multirow{2}{*}{$p=0.365$} \\
\hline No & $14(32.6)$ & $13(23.2)$ & $27(27.3)$ & \\
\hline \multicolumn{5}{|c|}{ Daily consumption of vegetables } \\
\hline Yes & $30(69.8)$ & $41(73.2)$ & $71(71.7)$ & \multirow{2}{*}{$p=0.823$} \\
\hline No & $13(30.2)$ & $15(26.8)$ & $28(28.3)$ & \\
\hline \multicolumn{5}{|c|}{ Meal frequency (including snacks), times/day } \\
\hline Three & $5(11.6)$ & $2(3.6)$ & $7(7.1)$ & \multirow{4}{*}{$p=0.068$} \\
\hline Four & $18(41.9)$ & $30(53.6)$ & $48(48.5)$ & \\
\hline Five & $11(25.6)$ & $20(35.7)$ & $31(31.3)$ & \\
\hline More than five & $9(20.9)$ & $4(7.1)$ & $13(13.1)$ & \\
\hline \multicolumn{5}{|l|}{ Eating out } \\
\hline Once weekly & $14(32.6)$ & $20(35.7)$ & $34(34.3)$ & \multirow{3}{*}{$p=0.136$} \\
\hline 2-4 times weekly & $9(20.9)$ & $20(35.7)$ & $29(29.3)$ & \\
\hline Never & $20(46.5)$ & $16(28.6)$ & $36(36.4)$ & \\
\hline \multicolumn{5}{|l|}{ Food label reading } \\
\hline Yes, always & $27(62.8)$ & $31(55.4)$ & $58(58.6)$ & \multirow{4}{*}{$p=0.860$} \\
\hline Sometimes & $12(27.9)$ & $17(30.4)$ & $29(29.3)$ & \\
\hline Rarely & $2(4.7)$ & $5(8.9)$ & $7(7.1)$ & \\
\hline Never & $2(4.7)$ & $3(5.4)$ & $5(5.1)$ & \\
\hline \multicolumn{5}{|l|}{ Smoking status } \\
\hline Smoking before pregnancy & $8(18.6)$ & $17(30.4)$ & $25(25.3)$ & \multirow{3}{*}{$p=0.082$} \\
\hline Smoking during pregnancy & $1(2.3)$ & $3(5.4)$ & $4(4.0)$ & \\
\hline Never & $34(79.1)$ & $36(64.3)$ & $70(70.7)$ & \\
\hline
\end{tabular}

${ }^{a}$ p-value was calculated by Chi-square test; ${ }^{*}$ The sum of the percentages for some of the items may exceed 100 due to rounding.

\section{Discussion}

Based on the results of the present survey, it could be summarized that there were no significant differences in the diabetes self-management between the two groups of women. Inconsistency in SMBG was observed among women with GDM. Strict in this regard were women with GDM who were receiving insulin therapy. In randomized controlled trial, Homko et al. examined the effect of SMBG on pregnancy outcomes and emotional status in women with GDM treated with medical nutrition therapy [21]. The investigators found that there was no significant difference in the effect of SMBG on feelings of self-efficacy, dietary compliance, pregnancy 
outcomes and neonatal complications. Both groups of pregnant women-the experimental one, performing daily monitoring, and the control one, performing periodic monitoring in prenatal visits, have achieved very good glycemic control [21]. In a recent randomized study, Mendez-Figueroa et al. suggested that among women with well-controlled GDM, performing blood glucose measurements every other day does not lead to increased birth weight [22]. Furthermore, the observed group increased compliance with testing compared with women who performed daily blood glucose measurements [22].

Table 4. Physical activity habits of the survey respondents.

\begin{tabular}{lllrl}
\hline Characteristics & $\begin{array}{l}\text { PDM group } \\
(n=43)\end{array}$ & $\begin{array}{l}\text { GDM } \\
(n=56)\end{array}$ & group $\begin{array}{l}\text { Total } \\
(n=99)\end{array}$ & p-value ${ }^{a}$ \\
\cline { 2 - 3 } & $N(\%)^{*}$ & $N(\%)^{*}$ & $N(\%)^{*}$
\end{tabular}

\begin{tabular}{|c|c|c|c|c|}
\hline \multicolumn{5}{|c|}{ Any physical activity } \\
\hline Yes & $31(72.1)$ & $46(82.1)$ & 77 (77.8) & $p=0.330$ \\
\hline No & $12(27.9)$ & $10(17.9)$ & $22(22.2)$ & \\
\hline
\end{tabular}

Physical activity frequency, times/week

\begin{tabular}{llll}
\hline 0 & $12(27.9)$ & $10(17.9)$ & $22(22.2)$ \\
\cline { 1 - 3 } 1-2 times & $10(23.3)$ & $14(25.0)$ & $24(24.2)$ \\
\hline 3-4 times & $12(27.9)$ & $13(23.2)$ & $25(25.3)$ \\
\hline 5-6 times & $4(9.3)$ & $6(10.7)$ & $10(10.1)$ \\
\hline every day & $5(11.6)$ & $13(23.2)$ & $18(18.2)$ \\
\hline
\end{tabular}

Duration of performed physical activity

\begin{tabular}{llll}
\hline 0 & $12(27.9)$ & $10(17.9)$ & $22(22.2)$ \\
\hline $1-10 \mathrm{~min}$ & $1(2.3)$ & $0(0.0)$ & $1(1.0)$ \\
\hline $11-15 \mathrm{~min}$ & $3(7.0)$ & $2(3.6)$ & $5(5.1)$ \\
\hline $16-30 \mathrm{~min}$ & $12(27.9)$ & $13(23.2)$ & $25(25.3)$ \\
\hline$>30 \mathrm{~min}$ & $15(34.9)$ & $31(55.4)$ & $46(46.5)$
\end{tabular}

ap-value was calculated by Chi-square test

*The sum of the percentages for some of the items may exceed 100 due to rounding

The main barriers to perform regular SMBG in women with GDM involved in the present study may be related to the cost of meters and test strips. It is not reimbursed by the Bulgarian National Health Insurance Fund for patients with dietcontrolled GDM. Other barriers for lower patient adherence to SMBG include lower socio-economic status, pain and discomfort when measuring, phobia of needles, etc. [14]. Therefore, the first step towards successful management of GDM is to focus on education of SMBG. These women should be appropriately educated on all aspects of the use of blood glucose meters and test strips-wash their hands before testing, apply the correct amount of blood to the test strip, and properly store the test strips after opening the vial [14]. Despite the benefits of SMBG, the recommendations to verify the accuracy of home blood glucose meters in regular intervals, should not be forgotten [23].
In the present study women with PDM have reported regular SMBG. This is probably due to the longer duration of diabetes and better knowledge about importance of SMBG. Insulin treatment is another reason for frequent SMBG.

In regards to eating habits, it was observed that few of pregnant women in both groups have visited a registered dietitian. In this survey more than $90 \%$ of women with GDM reported eating healthy balanced meals $(\mathrm{p}=0.001)$. Previous studies have been suggested that low-glycemic index diet in women with GDM could reduce the need for insulin [24]. Hui et al. reported that women with GDM who were treated with insulin experienced significantly higher levels of perceived stress and anxiety related to dietary management [25].

The lower percentage in PDM group regarding consumption of healthy meals, is most likely related to the fact that their treatment is predominantly based on insulin and relies mainly on pharmacotherapy to ensure good glycemic control.

Physical inactivity was observed in both groups. The beliefs such as 'exercise could be harmful to the baby' may cause barriers to performing physical exercise during pregnancy. Other personal concern of pregnant women may be related to the possible risk of hypoglycemia, especially in those treated with insulin. Healthcare professionals should focus more on providing additional information about safe and correct performance of physical exercise during pregnancy.

\section{Conclusion}

Our findings reveal the shortcomings and difficulties in the self-management of diabetes during pregnancy. The study confirms the importance of diabetes self-care and healthy lifestyle habits during pregnancy. Every pregnant woman with PDM or GDM should receive appropriate diabetes selfmanagement education and support. There is a need to raise women's awareness of the benefits of changing lifestyle during pregnancy, as well as revealing the importance of SMBG.

\section{References}

1. International Diabetes Federation. IDF Diabetes Atlas (8th Edn.). Brussels, Belgium.

2. Wahabi HA, Esmaeil SA, Fayed A, Al-Shaikh G, Alzeidan RA. Pre-existing diabetes mellitus and adverse pregnancy outcomes. BMC Res Notes 2012; 5: 496.

3. Bell R, Bailey K, Cresswell T, Hawthorne G, Critchley J, Lewis-Barned N, Northern Diabetic Pregnancy Survey Steering Group. Trends in prevalence and outcomes of pregnancy in women with pre-existing type I and type II diabetes. BJOG Int J Obstetr Gynaecol 2008; 115: 445-452.

4. Maresh MJ, Holmes VA, Patterson CC, Young IS, Pearson DW, Walker JD, McCance DR, Diabetes and Preeclampsia Intervention Trial Study Group. Glycemic targets in the second and third trimester of pregnancy for women with type 1 diabetes. Diabetes Care 2015; 38: 34-42. 
5. Macintosh MC, Fleming KM, Bailey JA, Doyle P, Modder J, Acolet D, Golightly S, Miller A. Perinatal mortality and congenital anomalies in babies of women with type 1 or type 2 diabetes in England, Wales, and Northern Ireland: population based study. BMJ 2006; 333: 177.

6. Mihaylova A, Uchicova E, Parahuleva N, Parahuleva M. Prevention of hyaline membrane disease (hmd) in preterm infants. World J Pharmacy Pharm Sci 2016; 5: 9-16.

7. Mihaylova A, Uchicova E, Parahuleva N, Gueorguiev S. Use of corticosteroids to prevent complications in preterm birth. PHARMACIA 2016; 63: 42-51.

8. Diabetes Canada Clinical Practice Guidelines Expert Committee. Diabetes Canada 2018 Clinical Practice Guidelines for the Prevention and Management of Diabetes in Canada. Can J Diabetes 2018; 42: 1-325.

9. American Diabetes Association. Management of diabetes in pregnancy: standards of medical care in diabetes-2018. Diabetes Care 2018; 41: 137-143.

10. National Institute for Health and Clinical Excellence. Diabetes in pregnancy: management from preconception to the postnatal period. NICE guideline (NG3) 2015.

11. Hod M, Kapur A, Sacks DA, Hadar E, Agarwal M, Di Renzo GC, Roura LC, McIntyre HD, Morris JL, Divakar $\mathrm{H}$. The International Federation of Gynecology and Obstetrics (FIGO) Initiative on gestational diabetes mellitus: a pragmatic guide for diagnosis, management, and care. Int J Gynecol Obstet 2015; 131: 173-211.

12. Clement $\mathrm{S}$. Diabetes self-management education. Diabetes Care 1995; 18: 1204-1214.

13. Mulholland C, Njoroge T, Mersereau P, Williams J. Comparison of guidelines available in the United States for diagnosis and management of diabetes before, during, and after pregnancy. J Womens Health 2007; 16: 790-801.

14. Negrato CA, Zajdenverg L. Self-monitoring of blood glucose during pregnancy: indications and limitations. Diabetol Metab Syndr 2012; 4: 54.

15. Hawkins JS, Casey BM, Lo JY, Moss K, McIntire DD, Leveno KJ. Weekly compared with daily blood glucose monitoring in women with diet-treated gestational diabetes. Obstet Gynecol 2009; 113: 1307-1312.

16. Jovanovic LG. Using meal-based self-monitoring of blood glucose as a tool to improve outcomes in pregnancy complicated by diabetes. Endocr Pract 2008; 14: 239-247.
17. Castorino K, Jovanovia L. Pregnancy and diabetes management: advances and controversies. Clin Chem 2011; 57: 221-230.

18. Ramachenderan J, Bradford J, McLean M. Maternal obesity and pregnancy complications: a review. Aust N Z J Obstet Gynaecol 2008; 48: 228-235.

19. Dennedy MC, Dunne F. The maternal and fetal impacts of obesity and gestational diabetes on pregnancy outcome. Best Pract Res Clin Endocrinol Metab 2010; 24: 573-589.

20. Kitzmiller JL, Block JM, Brown FM, Catalano PM, Conway DL, Coustan DR, Gunderson EP, Herman WH, Hoffman LD, Inturrisi M, Jovanovic LB. Managing preexisting diabetes for pregnancy: summary of evidence and consensus recommendations for care. Diabetes Care 2008; 31: 1060-1079.

21. Homko CJ, Sivan E, Reece EA. The impact of selfmonitoring of blood olucose on self-efficacy and pregnancy outcomes in women with diet-controlled gestational diabetes. Diabetes Educ 2002; 28: 435-443.

22. Mendez-Figueroa H, Schuster M, Maggio L, Pedroza C, Chauhan SP, Paglia MJ. Gestational diabetes mellitus and frequency of blood glucose monitoring: a randomized controlled trial. Obstet Gynecol 2017; 130: 163-170.

23. Henry MJ, Major CA, Reinsch S. Accuracy of selfmonitoring of blood glucose: impact on diabetes management decisions during pregnancy. Diabetes Educ 2001; 27: 521-529.

24. Moses RG, Barker M, Winter M, Petocz P, Brand-Miller JC. Can a low-glycemic index diet reduce the need for insulin in gestational diabetes mellitus? A randomized trial. Diabetes Care 2009; 32: 996-1000.

25. Hui AL, Sevenhuysen G, Harvey D, Salamon E. Stress and anxiety in women with gestational diabetes during dietary management. Diabetes Educ 2014; 40: 668-677.

\section{*Correspondence to}

Penka Petleshkova

Department of Obstetrics and Gynecology

Medical University-Plovdiv

Bulgaria 